\title{
Dry sliding wear behavior of Al 6082 metal matrix composites reinforced with red mud particles
}

\author{
Priyaranjan Samal ${ }^{1}$ [D $\cdot$ Ravi Kumar Mandava ${ }^{2} \cdot$ Pandu R. Vundavilli $^{1}$
}

Received: 16 December 2019 / Accepted: 29 January 2020 / Published online: 31 January 2020

(c) Springer Nature Switzerland AG 2020

\begin{abstract}
The present study aims at investigating the dry sliding wear behavior of Al-based 6082 metal matrix composites (AMMCs) reinforced with red mud particles by pin-on-disc configuration. AMMCs were fabricated with three different weight fractions of red mud particles ranging from 2 to $6 \%$ by using the stir-casting method. The friction coefficients and volumetric wear rates were continuously evaluated under normal loads of $10-30 \mathrm{~N}$ and sliding speed of $1.5 \mathrm{~m} \mathrm{~s}^{-1}$ for the constant sliding distance of $1000 \mathrm{~m}$. Microstructural analysis indicated that red mud particles are more or less uniformly dispersed throughout the Al matrix with minimal agglomeration. Experimental data shows that microhardness and tensile strengths of both the as-cast and heat-treated composites are steadily improved by increasing the amount of reinforced red mud particles but at the cost of ductility. Analysis of worn surfaces revealed that delamination and abrasion are dominant wear mechanisms for the case of the heat-treated composites are whereas the adhesion wear mechanism for the base alloy. The composite containing $4 \%$ red mud particles experienced the lowest wear rate at a normal load of $30 \mathrm{~N}$ and sliding speed of $1.5 \mathrm{~m} \mathrm{~s}^{-1}$ as compared to other composites including the base alloy. While the composite with $2 \%$ red mud particles shows the lowest friction coefficient, base alloy exhibited the highest friction coefficient.
\end{abstract}

Keywords AA6082 $\cdot$ Red mud·Stir casting $\cdot$ Microstructure $\cdot$ Mechanical $\cdot$ Wear

\section{Introduction}

In recent years, lightweight aluminum metal matrix composites (AMMCs) have received significant interest among the transportation industries owing to tailorable mechanical properties and better fuel economy. Most of the AMMCs are commonly reinforced with inorganic materials namely; carbide, boride, and alumina [1-3]. Unlike the synthesis of these ceramic particles need the controlled chemical environment at elevated temperatures, red mud particles are produced from industrial waste as a byproduct which facilitates energy saving and low cost [4]. Moreover, the particle size of red mud particles is available in the nano-scale regime $(50-200 \mathrm{~nm})$ which tends to enhance the strength and tribological behavior of the composites [5]. In general, red mud is one of the most abundant insoluble solid waste resulting from mineral processing of bauxite ore to produce alumina. It consists of iron, silica, titanium and parts of the bauxite ore along with some other minor elements. Lack of waste management of red mud particles is still an environmental issue which causes drastic climate change on the earth [6]. Moreover, red mud particles are being used in various engineering applications such as removal of the sulfur compound from kerosene oil, $\mathrm{pH}$ modifier in the leaching of gold ores, production of radiopaque materials, and preparation of catalysts, pigments and anti-corrosion paints for the marine vehicles [7-10].

Priyaranjan Samal, ps23@iitbbs.ac.in | 'School of Mechanical Sciences, Indian Institute of Technology Bhubaneswar, Bhubaneswar 752050, India. ${ }^{2}$ Department of Mechanical Engineering, Vignan's Foundation for Science, Technology and Research, Guntur 522213, India. 
Stir-casting is the most common, economical and highly reproducible method used to fabricate metal matrix composites [11, 12]. Furthermore, Singla et al. [5] enhanced the dry sliding behaviour of 6061 Al-alloy after reinforcing with variants of ceramic particles such as $\mathrm{SiC}$, red mud and $\mathrm{Al}_{2} \mathrm{O}_{3}$ by the stir-casting method. Saravanan et al. [13] adopted stir casting method for fabricating TiC reinforced Al 6063 metal matrix composites. It was reported that the homogenous distribution of titanium carbide particles led to the improvement of hardness properties. The wear rate of the composited reduced exhibiting better wear resistance of the MMCs. Kumar et al. [14] studied the effects of weight fraction of red mud particles on dry sliding wear behaviour of Al6061/Alumina/Graphite hybrid metal matrix composites. They found that wear resistance of $11 \mathrm{wt} \%$ of red mud particles was enhanced by about $90 \%$ when compared to that of Al6061 hybrid MMCs. The wear resistance of Al 6061 MMCs incorporated with fly ash particles was improved significantly whereas the strengthening mechanism led to the enhancement of hardness in the composites [15]. Basavarajappa et al. [16] studied the effect of $\mathrm{SiC}$ particles on the wear behaviour of Al2219/Gr hybrid composites and found that the wear resistance was enhanced with the addition of $\mathrm{SiC}$ whereas the wear rate was decreased. Samal et al. [17] studied the wear properties of AA5052 MMCs reinforced with titanium carbide through in situ reaction method. With addition of $\mathrm{TiC}$, the wear resistance of the composites was significantly improved. Moreover, the tensile strength and hardness were also seen to be enhanced as a result of clear interface bonding between the matrix and reinforcement. Kar and Surekha [18] fabricated AA7075 based hybrid composites reinforced with $\mathrm{TiC}$ and red mud through stir casting process. With increase in the applied load and sliding distance, the wear loss of the composites was increased as compared to the base alloy. Dwiwedi et al. [19] studied the wear behavior of AA6061 composites reinforced with mussel shell particles where they reported that the sliding wear behavior of the composites was improved as a result of the addition of the mussel shell particles. The wear rate of the MMCs was reduced with higher sliding distances for different loading conditions whereas the cumulative wear loss was increased. Similarly, Bhasha and Balamurugan [20] studied the mechanical properties of the 6061 hybrid composites reinforced with TiC and rice husk ash. It was observed that the tensile strength and hardness were enhanced whereas a reduction in the impact strength of the composites was occurred. Improvement in the mechanical properties was attributed to the homogenous distribution of the reinforcement particles in stir casting process.

Literature study shows that most of the researchers had focused on improving the dry sliding wear behaviour of AMMCs after reinforcing them with various ceramic particles for a variety of engineering applications. Most of the reported work investigated the influence of operating parameters on the dry sliding behaviour of AMMCs. On the other hand, least attention was paid in a way to understand the nature of dominant wear mechanism during dry sliding condition and microstructure-wear property correlation especially for the case of Al-6082 matrix composites containing nano-sized red mud particles. The main objective of the present study is to utilize the red mud, which is an industrial waste, in fabrication of aluminum composites. Furthermore, an attempt is made to understand how the wear behavior of the composites on addition of red mud. Since Al 6082 alloy is more prone to micro-segregation of solute atoms during the casting process, T6 heat treatment is employed to achieve homogenous microstructures with improved mechanical properties before the dry sliding wear test. The mechanical properties such as micro-hardness, tensile strength, and impact strength are also evaluated for both the composites in heat-treated and as-casted condition.

\section{Materials and methods}

In the present work, commercially available Aluminum alloy 6082 was considered as the matrix material and was procured from Venuka Engineering Pvt. Ltd, Hyderabad, India. AA6082 series is primarily alloyed with magnesium and silicon and is a heat treatable material. It finds its usage in many structural application due to its excellent strength properties. The detail composition of AA6082 which is used in this work is given in Table 1. Red mud which is a waste product in extraction of bauxite, having particle sizes in the range of $500 \mathrm{~nm}$ to $50 \mu \mathrm{m}$ was chosen as the reinforcement phase and was procured from NALCO Damanjodi, India. Chemical compositions of the red mud particles are given in Table 2. The micrograph of the red mud particles is given in Fig. 1.

Initially, as-cast aluminum alloy 6082 ingot was cut into small sizes ( $30 \mathrm{~mm} \times 30 \mathrm{~mm} \times 30 \mathrm{~mm}$ ) so that it can be fit into the crucible followed by removing oxide film surfaces if any. The required amount of Al alloy blocks according to
Table 1 Chemical composition of AA6082

SN Applied Sciences A SPRINGER NATURE journal

\begin{tabular}{lllllllll}
\hline Element & $\mathrm{Mg}$ & $\mathrm{Si}$ & $\mathrm{Cr}$ & $\mathrm{Fe}$ & $\mathrm{Zn}$ & $\mathrm{Mn}$ & $\mathrm{Ti}$ & $\mathrm{Al}$ \\
\hline wt\% & 1.05 & 1.21 & 0.02 & 0.16 & 0.02 & 0.74 & 0.08 & Remainder \\
\hline
\end{tabular}


Table 2 Chemical composition of Red mud

\begin{tabular}{lllllll}
\hline Element & $\mathrm{Al}_{2} \mathrm{O}_{3}$ & $\mathrm{Fe}_{2} \mathrm{O}_{3}$ & $\mathrm{SiO}_{2}$ & $\mathrm{TiO}_{2}$ & $\mathrm{Na}_{2} \mathrm{O}$ & $\mathrm{CaO}$ \\
\hline wt\% & 23.7 & 44.5 & 6.3 & 15.8 & 5.1 & 4.6 \\
\hline
\end{tabular}

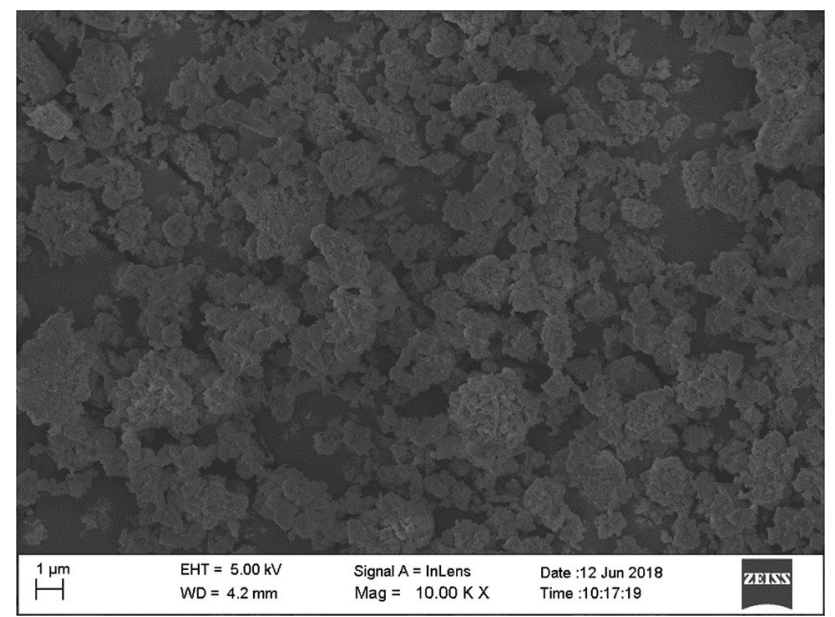

Fig. 1 SEM micrograph of red mud particles

stoichiometric calculation was melted in a graphite crucible using an electrical resistance furnace and raised the superheat temperature up to $800{ }^{\circ} \mathrm{C}$. Red mud particles with different weight fractions $(0 \%, 2 \%, 4 \%$, and $6 \%)$ were wrapped into an aluminum foil and pre-heated in another muffle furnace at a temperature of $400{ }^{\circ} \mathrm{C}$ to remove any moisture and gases present in it. Stirring was carried out by a 3-axial mechanical stirrer blade at a speed of $500 \mathrm{rpm}$, to which the pre-heated red mud particles were added. In order to achieve a homogeneous distribution of red mud in the aluminum melt, a vortex field was produced at higher rpm during the stirring action. This process of stirring was continued for another $15 \mathrm{~min}$ to achieve a uniform distribution of red mud. Hexachloroethane particles were mixed as degasser to the melt to remove any dissolved hydrogen gas and thus improving the efficiency of casting. Subsequently, the molten metal slurry was poured into a pre-heated mild steel mould and solidified. The ascasted composites were subjected to solutionizing at a temperature of $529^{\circ} \mathrm{C}$ for $1 \mathrm{~h}$, followed by air quenching, and then artificial aging at a temperature of $177^{\circ} \mathrm{C}$ for $8 \mathrm{~h}$. Both the as-cast and heat-treated (HT) composite samples were subjected to different experimentation in order to investigate the relationship between their microstructures and mechanical behaviour.

The microstructural analysis was carried out by a field emission scanning electron microscope (ZEISS Merlin Compact Gemini). For this, the composites specimen are thoroughly polished and undergone Keller's reagent etching process. The Vickers Micro-hardness test (OMNITECH semi-automatic) was used to assess the micro-hardness behaviour of the composite specimen at a load of $500 \mathrm{gf}$ for a dwell time of $10 \mathrm{~s}$. The surface of the samples were polished with emery paper to get precise hardness value. After the fabrication of the composites, the samples for tensile tests and impact tests are prepared using wirecut EDM process as per the ASTM-E8 standard $25 \mathrm{~mm}$ gauge length and $6 \mathrm{~mm}$ width. Tensile behaviour of the specimens was evaluated by a universal testing machine (TUE-C-200) in accordance with the above standard at a cross head speed of $0.5 \mathrm{~mm} / \mathrm{min}$ which is commonly used. Charpy impact test (Tinius Olsen 104) was employed to study the impact strength of the composites and the impact specimens are prepared according to the ASTM E23 standard of dimensions $55 \mathrm{~mm} \times 10 \mathrm{~mm} \times 10 \mathrm{~mm}$. To carry out the charpy impact test, a v-notch is prepared at the center of the length of the specimen. To ensure repeatability, each of the tests were carried out three times, such that the reported value is an average of three observations.

After evaluating the hardness and tensile behaviour, it can be observed that in both the cases the $\mathrm{T}_{6}$ heattreated specimens achieved better performance compared to the as-casted specimens. Further, dry sliding wear performance in accordance with ASTM G99-04 standard was evaluated for both the as-cast and heattreated composite pin samples in a pin-on-disc (DUCOM TR-20M-106) apparatus. As-cast aluminum composite samples were machined from the rectangular fabricated castings to have a square-shaped cross-section of $6 \mathrm{~mm}$ length and a height of $30 \mathrm{~mm}$ to carry out the dry sliding tests. The counter-face disc is made up of EN31 hardened steel (diameter and thickness 90 and $5 \mathrm{~mm}$, respectively). The end of the pins was polished and cleaned with acetone solution in an ultra-sonicator before performing the wear tests. The dry sliding tests were conducted by varying the normal loads of $10-30 \mathrm{~N}$ and sliding speeds of $1.5 \mathrm{~m} \mathrm{~s}^{-1}$ for the constant sliding distance of $1000 \mathrm{~m}$ under the ambient room condition. With the help of a weighing balance of accuracy $0.0001 \mathrm{~g}$, the weight of the pins was measured and documented before and after each test. From the wear set up, the height loss is shown for continuously on the monitor interface. By multiplying the cross-sectional area with height loss of the wear specimen, the volumetric loss can be measured. Wear debris particles were also collected for morphological characterization. Considering the difference between the volumetric losses per total sliding distance before and after the tests, wear rate was calculated. In order 
to measure the coefficient of friction (COF) between the sliding surfaces of contact, normal force and friction force were recorded by a load cell continuously. The ratio between the tangential friction force and normal applied load gives the value of coefficient of friction between the contact surfaces. The graphical representation of stir casting set up with microstructural analysis, mechanical and wear experiments is shown in Fig. 2.

\section{Results and discussion}

\subsection{Microstructural analysis}

Figure 3 shows the microstructural characteristics of the as-cast AA6082 alloy specimen with different weight percentages of red mud particles. The composites exhibit uniform dispersion of red mud particles throughout the matrix alloy irrespective of the weight percentages of the red mud particles added during composite fabrication. This means that good wettability is maintained between the molten alloy and red mud particles during stir cast process. Figure 4 represents the EDX spectra of the as-cast specimen with different weight percentages of the red mud particles. It can be noticed that while the base alloy of AA6082 specimen shows the presence of Al, $\mathrm{Mg}$, and Si peaks, the composite specimen depicts the additional peaks of $\mathrm{Ca}, \mathrm{Fe}, \mathrm{Mn}$, and $\mathrm{Cr}$. Such difference in EDX spectra indicates that presence of red mud particles and dispersed properly throughout the molten slurries during composite fabrication.

\subsection{Mechanical behavior}

Figure 5 shows the Vickers micro hardness data for both the as-cast and $T_{6}$ heat-treated AA6082 alloy specimen with different weight percentages of red mud particles. It can be observed that hardness of both the as-cast and $\mathrm{T}_{6}$ heat-treated specimen increases monotonically with increasing weight percentages of the red mud particles. Such an increase in hardness could be attributed to an increase in the intensity of impeding the dislocation movement by the red mud particles. Moreover, the hardness of the $\mathrm{T}_{6}$ heat-treated composites is significantly higher than that of the as-cast composites. This happens because of the fact that the dislocation movement can be hindered effectively by the formation of the secondary phase precipitates during the aging process.

Table 3 summaries the tensile properties of both the ascast and $T_{6}$ heat-treated AA6082 alloy specimen with different weight percentages of red mud particles. It can be seen that the yield strength and ultimate tensile strength increase with increasing the weight percentage of red mud particles. It was observed that a $20 \%$ increase in the ultimate tensile strength of the $6 \% \mathrm{MMCs}$ as compared to that of the base alloy. Similarly, $26 \%$ enhancement in the yield strength was observed in case of the $\mathrm{Al} / 6 \%$ red mud composites. The increase in ultimate tensile strength indicates the better bonding of red mud particles with the soft aluminum matrix. A similar trend can be found by other researchers taking different reinforcement with aluminum matrix [17]. The resistance exhibited by red mud particles hindered the dislocation, thus enhancing the tensile strength by Orowan strengthening [21].
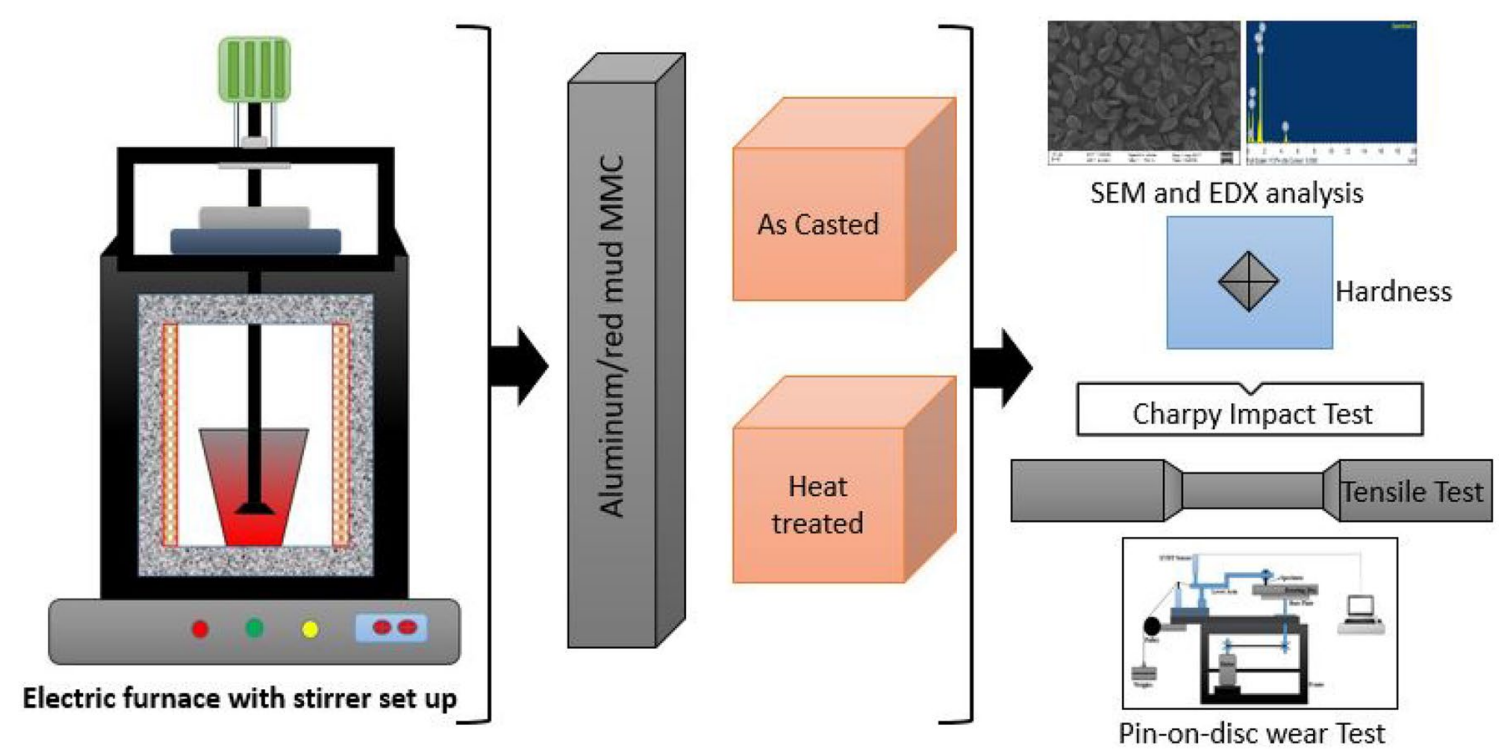

Fig. 2 Graphical representation of stir casting set up with experimental methodology 

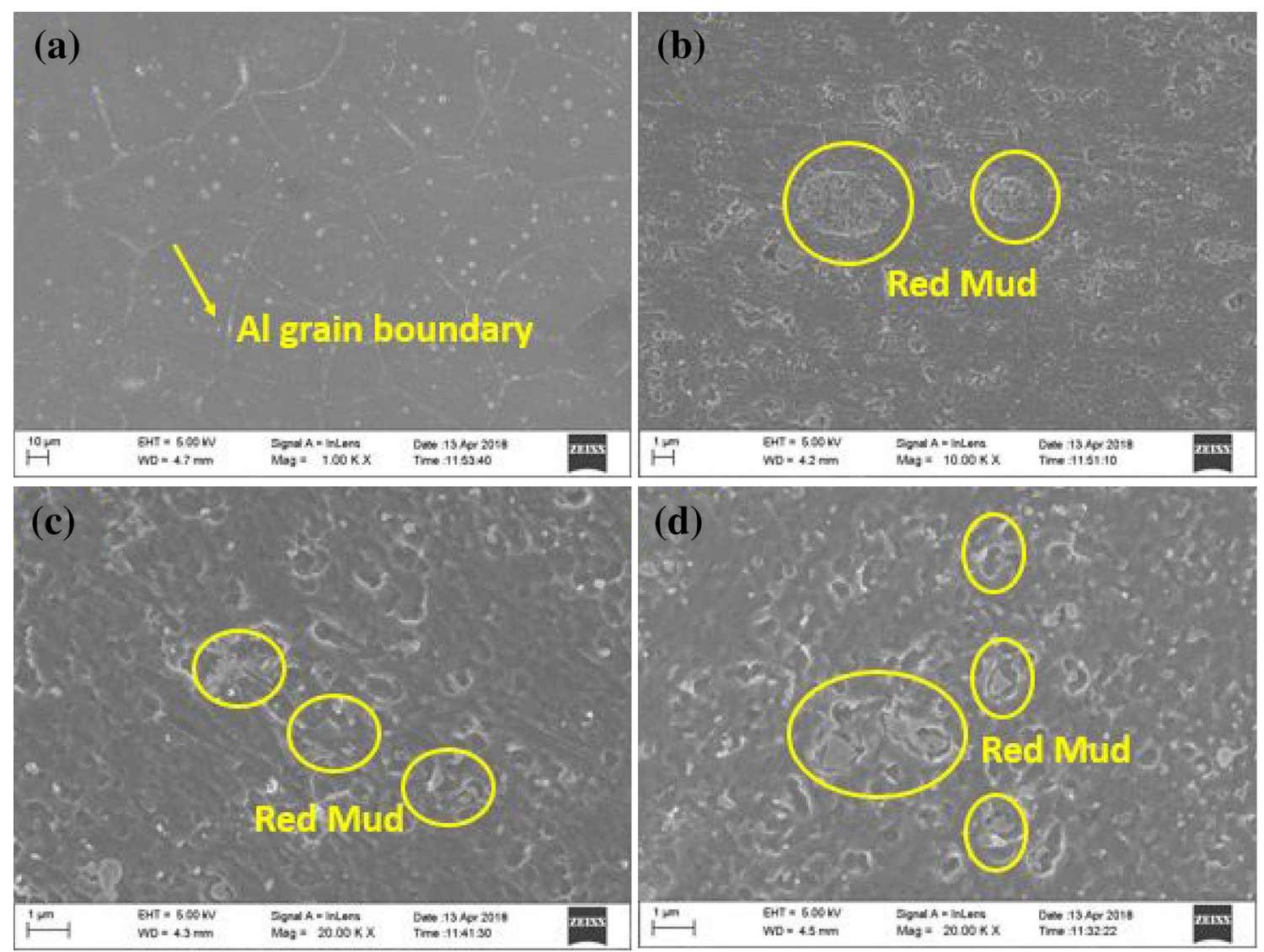

Fig. 3 SEM micrographs of the cast specimen with different weight percentages of the red mud particles a Al alloy, b $2 \%$ red mud, c $4 \%$ red mud, $\mathbf{d} 6 \%$ red mud
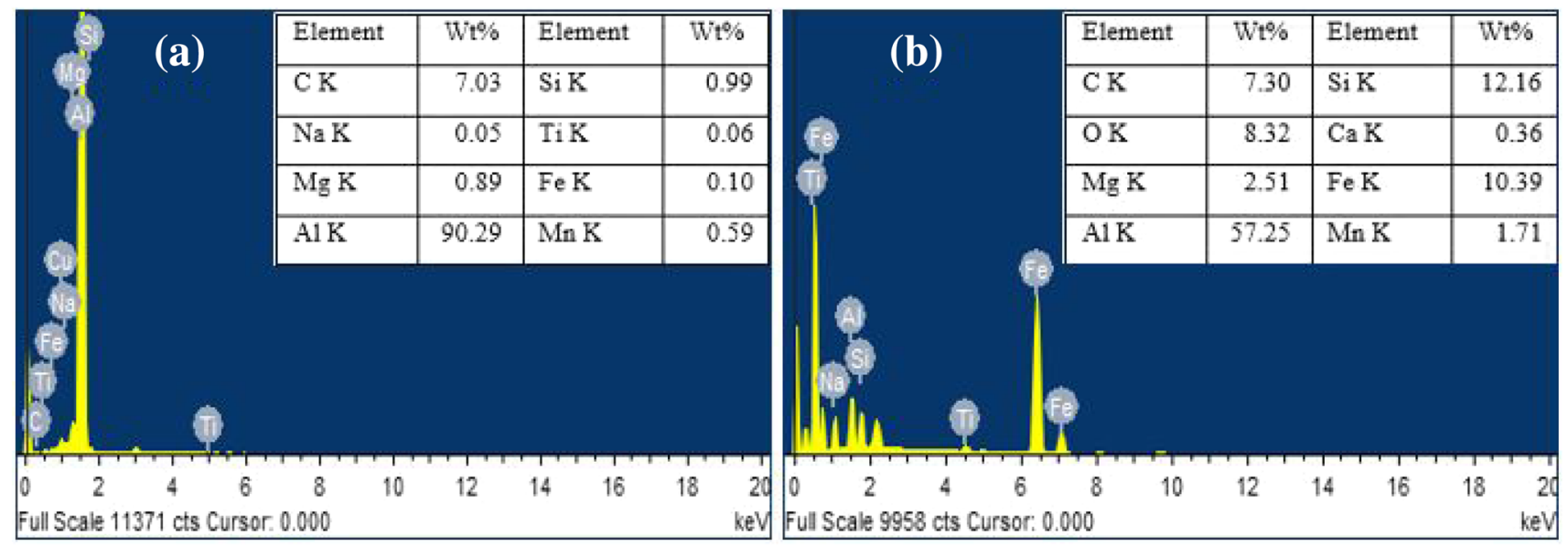

Fig. 4 EDX spectrum of a Al base alloy, b $6 \%$ red mud MMCs

Alternatively, the percentage of elongation or ductility of both the as-cast and $\mathrm{T}_{6}$ heat-treated composites decreases with increase in the amount of red mud particles. For instance, the percentage of elongation decreases up to a maximum of $17 \%$ and $13 \%$ for as-casted and heat-treated specimens, respectively. It is a well known fact that any increase in yield strength or ultimate tensile strength of the composites led to degrading their elongation capacity or ductility especially if these are reinforced with micron or sub-micron sized hard reinforcement particles. The 


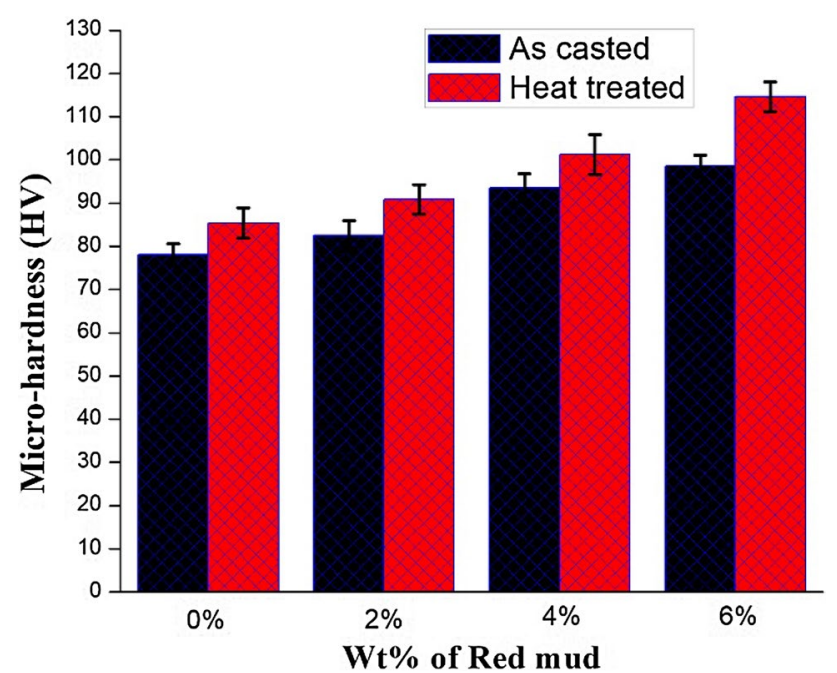

Fig. 5 Variation of microhardness of $\mathrm{Al} / \mathrm{red}$ mud MMCs

resistance provided by the red mud particles strengthened the composites by restricting dislocation movement. This restriction in dislocation movement caused better transfer of load between aluminum and red mud particles.

The effect of impact strength of AA6082/red mud composites is illustrated in Fig. 6. As compared to the base alloy, it was observed that the impact strength of the MMCs are reduced as a result of decrease on ductility. Moreover, the heat treated specimens exhibited better impact strength corresponding to their casted composites. A $38 \%$ reduction in the impact strength can be observed in case of $6 \%$ red mud MMCs in case of the as casted specimen whereas $32 \%$ reduction was exhibited in case of the heat treated composite specimen. The inclusion of red mud particles in the Al alloy enhanced the hardness, thus increasing the brittleness of the composites causing reduction in the impact energy. Moreover, the increase in hardness also helped in increasing the debonding energy causing more plastic deformation. These observations are well in line with the literatures available [3, 22]. Heat treatment i.e. first solutionizing is carried out to dissolve all the alloying element in solid solution of aluminum. In otherwards,

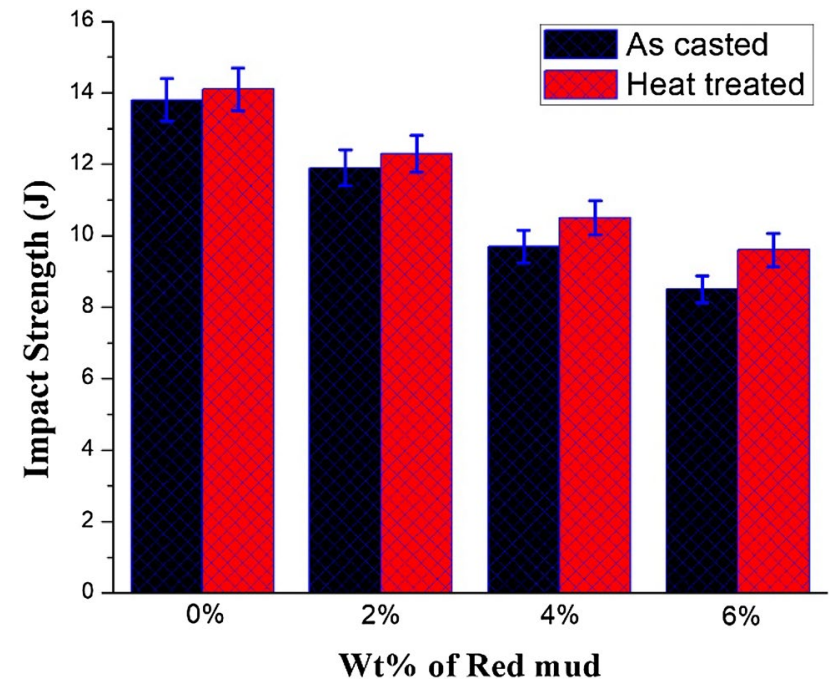

Fig. 6 Variation of impact strength of $\mathrm{Al} / \mathrm{red}$ mud MMCs

it enables the diffusion of alloying element to occur. During this artificial aging or age hardening, the high temperature enable the dislocation movement and diffusion successively. Afterwards it followed by quenching which restricts the precipitation to occur on cooling. These above phenomena strengthened the aluminum composites and yield better results.

Figure 7 represents the SEM micrographs of the fractured surfaces of base alloy and AA6082/red mud composite after tensile testing. It can be seen that the presence of equiaxed dimple features indicate that the specimen fails by ductile mode after a significant amount of plastic deformation for the case of AA6082 alloy (See Fig. 7a). On the other hand, the composites fail by mixed mode of fracture (ductile and brittle) due to the existence of cleavage facets and few dimples shown as in Fig. 7b, c. As seen from Fig. $4 d$, the presence of micro-voids indicates that crack nucleates via decohesion mechanism at the interface between the alloy matrix and red mud particles. The decrease in the size of dimples confirms that ductility of composites degrades with increasing the amount of red mud particles.
Table 3 Summary of the tensile properties for the investigated composites

\begin{tabular}{|c|c|c|c|c|c|c|}
\hline \multirow[t]{2}{*}{ wt $\%$ red mud } & \multicolumn{3}{|l|}{ As casted } & \multicolumn{3}{|l|}{ Heat-treated } \\
\hline & $\begin{array}{l}\text { Ultimate ten- } \\
\text { sile strength } \\
(\mathrm{MPa})\end{array}$ & $\begin{array}{l}\text { Yield } \\
\text { strength } \\
(\mathrm{MPa})\end{array}$ & $\%$ elongation & $\begin{array}{l}\text { Ultimate ten- } \\
\text { sile strength } \\
(\mathrm{MPa})\end{array}$ & $\begin{array}{l}\text { Yield } \\
\text { strength } \\
(\mathrm{MPa})\end{array}$ & $\%$ elongation \\
\hline $0 \%$ & 141.23 & 89.14 & 10.32 & 158.25 & 94.61 & 8.6 \\
\hline $2 \%$ & 148.68 & 94.72 & 8.81 & 162.54 & 99.36 & 7.45 \\
\hline $4 \%$ & 152.5 & 102.63 & 6.50 & 169.72 & 111.21 & 5.2 \\
\hline $6 \%$ & 169.87 & 112.05 & 5.12 & 179.50 & 119.35 & 4.53 \\
\hline
\end{tabular}



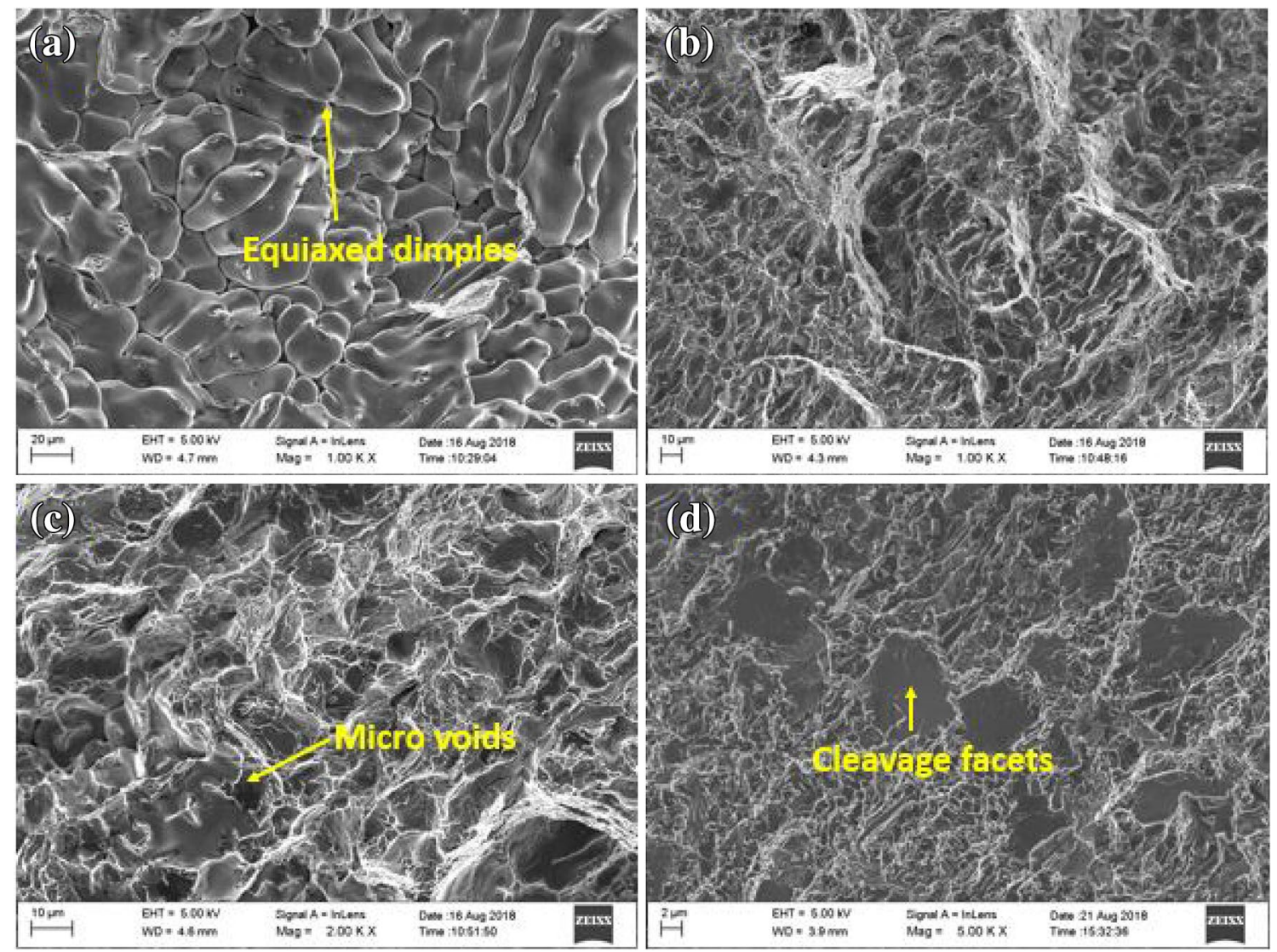

Fig. 7 Tensile fracture micrographs of composites with different weight percentages of the red mud particles a Al alloy, b $2 \%$ red mud, c $4 \%$ red mud, $\mathbf{d} 6 \%$ red mud

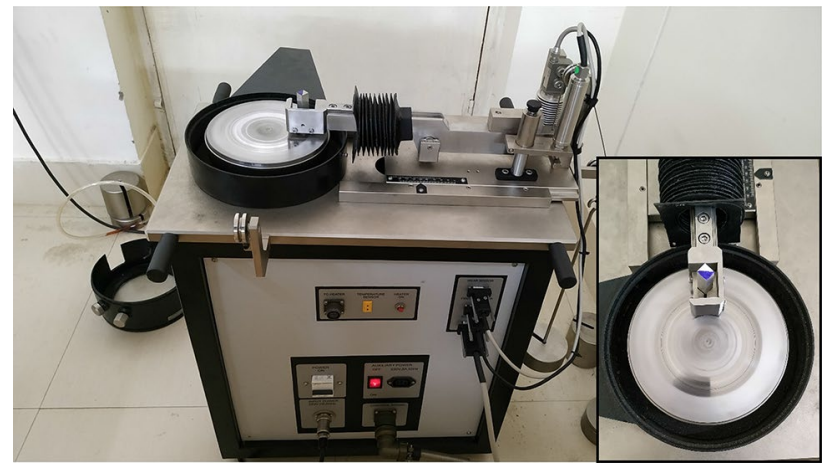

Fig. 8 The experimental set up of pin-on-disc wear test

\subsection{Wear behavior}

The experimental set up of pin-on-disc wear test is given in Fig. 8. The Fig. 9 illustrates the friction and wear behaviour of the $T_{6}$ heat-treated composites with different weight percentages of red mud particles under different normal load conditions ranging from 10 to $30 \mathrm{~N}$. At a very low load of $10 \mathrm{~N}$, the coefficient of friction of base alloy is high compared to that of the $\mathrm{T}_{6}$ heat-treated composites. With increase in the sliding distance the wear rate of the composited was seen to be reduced for all percentage of the composites. During the initial experiments, two sliding surfaces have sharp contacts which produce large stress. These sharp edges fractured and fragmented with plastic deformation [23] yielding higher wear rate. With higher sliding distance, the wear debris fill the valleys on the surfaces. Thus the reduction in the abrasive action occurs which lead to lower wear rate. According to the Bowdon and Tabor model [24], friction is consisting of two physical characteristics i.e. adhesion and ploughing. While the adhesion component develops from adhesive force existing between the contacting surfaces, ploughing component appears from the amount of plastic deformation between the surfaces of contact. Higher the hardness of the materials, lower the ploughing component of friction which results in less coefficient of friction. It is already mentioned that micro-hardness of the $T_{6}$ heat-treated composites is significantly higher than that of the base alloy. Therefore, the base alloy experiences a significant amount of plastic deformation or ploughing component which eventually tends to increase the coefficient of 

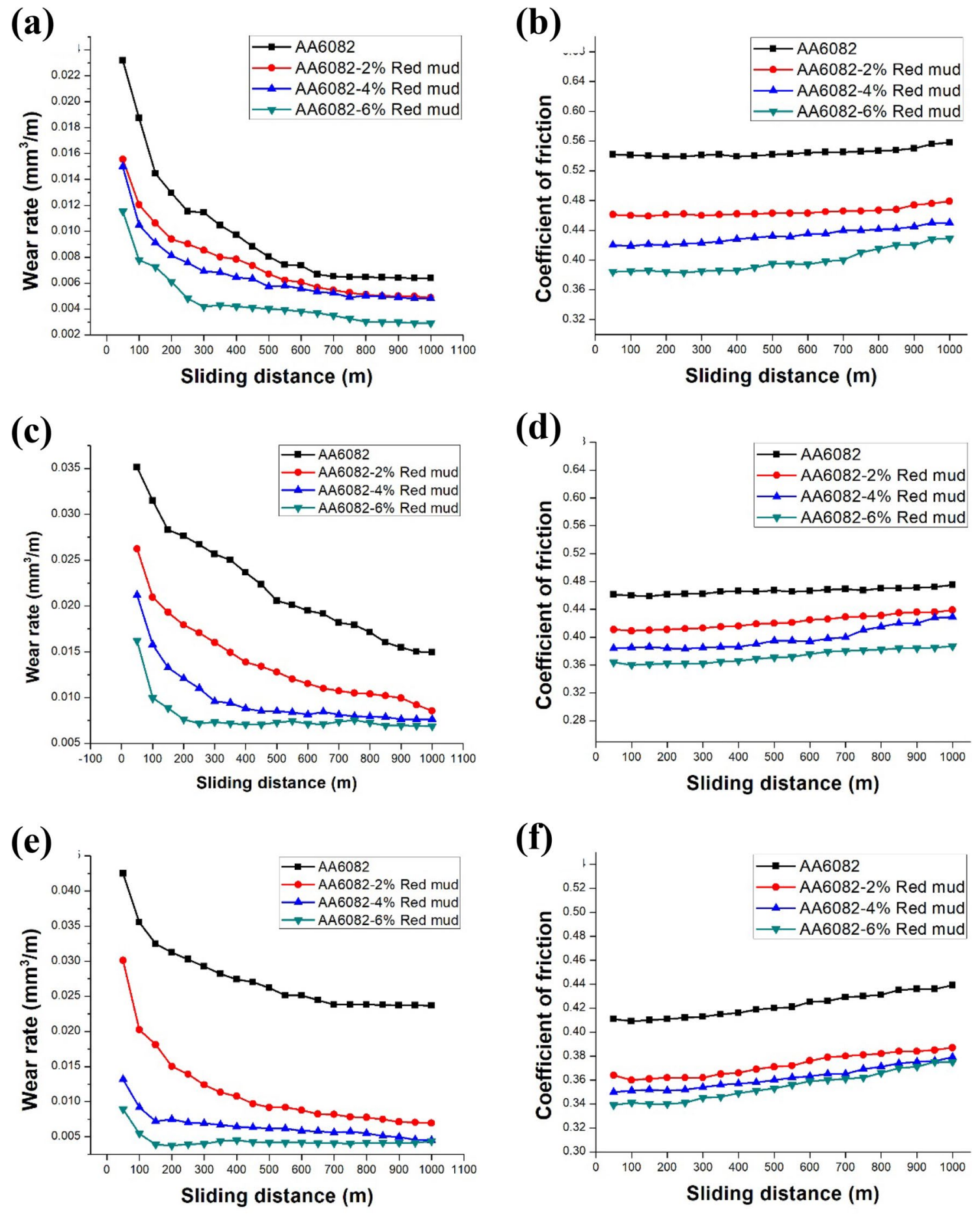

Fig. 9 Variation of wear rate and coefficient of friction of the T6 heat-treated composites under different normal load conditions $\mathbf{a}$, $\mathbf{b} 10 \mathrm{~N}, \mathbf{c}$, d $20 \mathrm{~N}$, and e, $\mathbf{f} 30 \mathrm{~N}$

friction. In fact, this increase in ploughing component of friction leads to the development of adhesive junctions at the contacting asperities during sliding contact if the oxidation tendency is very less. On the other hand, for the higher load conditions of 20 and $30 \mathrm{~N}$, the heat-treated composites having $6 \mathrm{wt} \%$ red mud particles exhibits a relatively high coefficient of friction when compared to other composites and base alloy. This could be probably due to the existence of third body abrasion where loosen wear particles get caught between the contacting surfaces 
during sliding contact. For the normal load conditions of 20 and $30 \mathrm{~N}$, the heat-treated composite having $6 \mathrm{wt} \%$ of red mud particles shows high friction coefficient when compared to other composites and the base alloy. However, this trend is being followed up to certain sliding distances ( $450 \mathrm{~m}$ and $600 \mathrm{~m}$ ), and thereafter, the base alloy starts showing a high friction coefficient. Such a change in frictional behaviour could be attributed to decrease in the extend of third body abrasion with increasing sliding distance as result of the compaction of loosened wear debris or the formation of tribolayer which tends to serve as a lubricant between the contacting surfaces of the heattreated composite and steel counter body. Conversely, the evolution of high friction coefficient with increasing sliding distance could be associated with the formation of several adhesive junctions at the contacting asperities for the case of base alloy. The effect of weight percentage of red mud particles on the friction behaviour is appeared to be advantageous up to $4 \%$ of red mud particles. This means an increase in hardness of the heat-treated composite generally decreases the ploughing component of friction on the pin surfaces. As the weight percentage of red mud particles increases, the number of protrusion of reinforcement particles also increases so that the friction behaviour of the heat-treated composite drastically changes from two body abrasion to third body abrasion. In fact, the existence of protrusion and cavities on the pin surface of the heat-treated composite provides the effective medium of entrapping the loosened wear debris to activate the mechanism of third body abrasion.

Figure 10 represents the worn surfaces of the heattreated composites with the different weight percentage of red mud particles at a normal load of $30 \mathrm{~N}$ and sliding speed of $1.5 \mathrm{~m} \mathrm{~s}^{-1}$. Analysis of worn surfaces indicates that delamination and abrasion are dominant wear mechanisms for the case of heat-treated composites whereas the adhesion wear mechanism is dominant for the base alloy. It can be suggested from the fact that aluminum reacts with iron in the EN31 steel disk to form an adhesive layer at the contacting asperities because of the high frictional temperature developed at the interface during sliding contact. The presence of shear-like crack features on the worn surfaces as denoted by arrows reveals that domination wear mechanism is delamination for the case
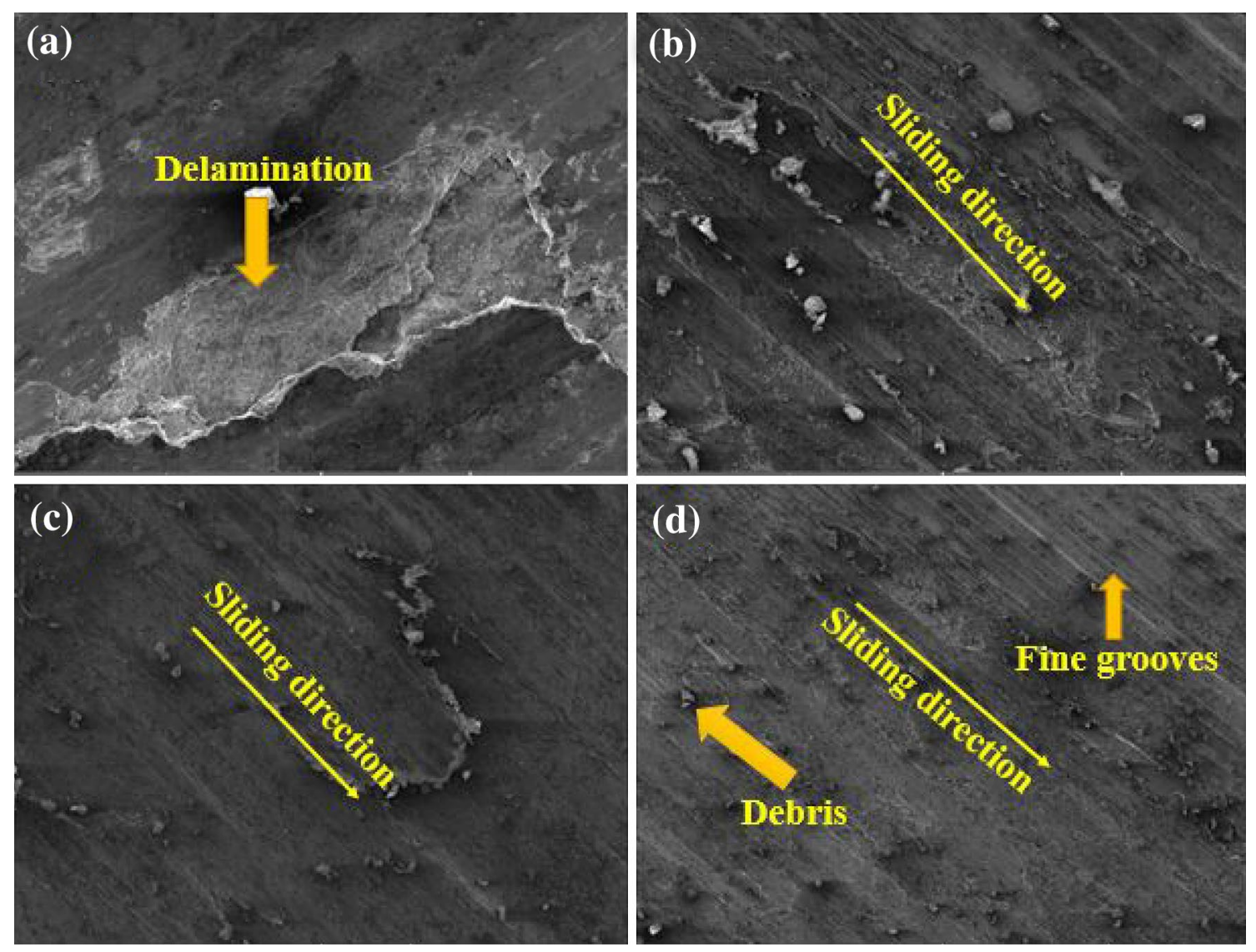

Fig. 10 SEM micrographs showing the worn surface of the T6 heat-treated composites a Al alloy, b $2 \%$ red mud, c $4 \%$ red mud, d $6 \%$ red mud 


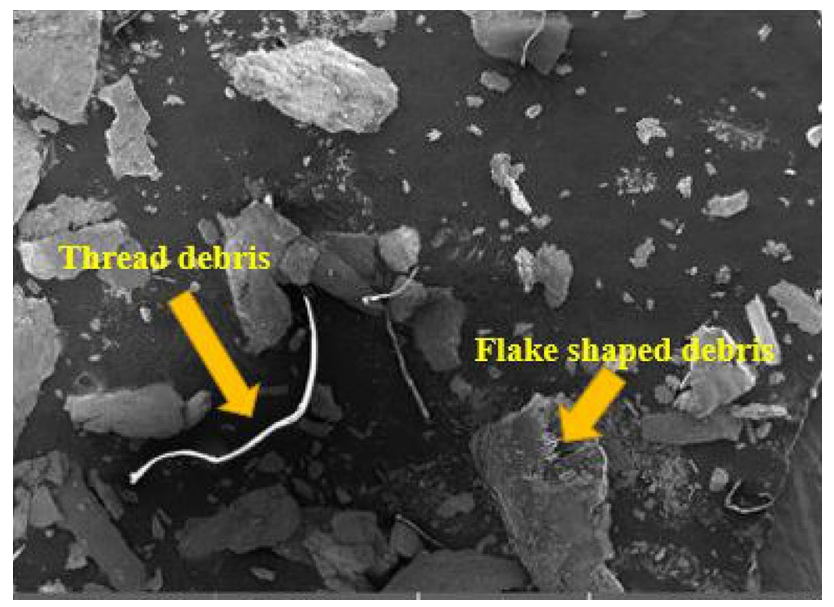

Fig. 11 SEM micrograph of collected wear debris

of base alloy. With an increase in the weight percentage of reinforcement particles, the enhanced load carrying ability and abrasion resistance of composites improved. Figure 11 shows the flake shaped and thread like debris collected during the sliding wear tests.

\section{Conclusions}

The following conclusions can be drawn from the current work based on the experimental observation:

a. Al-based metal matrix composites with different weight percentages of red mud particles were successfully fabricated by the stir casting method. The microstructural analysis confirmed the uniform dispersion of red mud particles throughout the matrix material.

b. With the addition of red mud particles, the micro-hardness, yield strength, and ultimate tensile strength are improved whereas the impact strength is decreased for both as casted and heat treated composites.

c. Wear rate of the composites reduced with the increase in the sliding distance whereas with higher content of red mud particles, the composites exhibited higher wear resistance. Worn surface analysis confirmed that delamination and abrasion are dominant wear mechanisms.

\section{Compliance with ethical standards}

Conflict of interest On behalf of all authors, the corresponding author states that there is no conflict of interest.

\section{References}

1. Bhoi NK, Singh H, Pratap S (2019) Developments in the aluminum metal matrix composites reinforced by micro/ nano particles-a review. J Compos Mater. https://doi. org/10.1177/0021998319865307

2. Nieto A, Yang H, Jiang L, Schoenung JM (2017) Reinforcement size effects on the abrasive wear of boron carbide reinforced aluminum composites. Wear 390-391(March):228-235

3. Samal P, Vundavilli PR (2019) Investigation of impact performance of aluminum metal matrix composites by stir casting. IOP Conf Ser Mater Sci Eng 653:012047

4. Samal S, Ray AK, Bandopadhyay A (2013) Proposal for resources, utilization and processes of red mud in India-a review. Int J Miner Process 118:43-55

5. Singla YK, Chhibber R, Bansal H, Kalra A (2015) Wear behavior of aluminum alloy 6061-based composites reinforced with $\mathrm{SiC}, \mathrm{Al}_{2} \mathrm{O}_{3}$, and red mud: a comparative study. JOM 67(9):2160-2169

6. Agrawal A, Sahu KK, Pandey BD (2004) Solid waste management in non-ferrous industries in India. Resour Conserv Recycl 42:99-120

7. Paramguru RK, Rath PC, Misra VN (2004) Trends in red mud utilization - a review. Miner Process Extr Metall Rev 26(1):1-29

8. Pera J, Boumaza R, Ambroise J (1997) Development of a pozzolanic pigment from red mud. Cem Concr Res 27(10):1513-1522

9. Pontikes Y, Angelopoulos GN (2013) Bauxite residue in cement and cementitious applications: current status and a possible way forward. Resour Conserv Recycl 73:53-63

10. Zhang M, Zhao M, Zhang G, Mann D, Lumsden K, Tao M (2016) Durability of red mud-fly ash based geopolymer and leaching behavior of heavy metals in sulfuric acid solutions and deionized water. Constr Build Mater 124:373-382

11. Pramod SL, Bakshi SR, Murty BS (2015) Aluminum-based cast in situ composites: a review. J Mater Eng Perform 24(June):2185-2207

12. Samal P, Vundavilli PR, Meher A, Mahapatra MM (2019) Fabrication and mechanical properties of titanium carbide reinforced aluminium composites. Mater Today Proc 18:2649-2655

13. Saravanan S, Ravichandran M, Balan AV, Senthilkumar P (2019) Synthesis and abrasive wear performance of stir cast AA6063TiC composite materials. SN Appl Sci 1(12):1-7

14. Kumar M, Megalingam A (2019) Tribological characterization of Al6061/alumina/graphite/redmud hybrid composite for brake rotor application. Part Sci Technol 37(3):261-274

15. Dinaharan I, Nelson R, Vijay SJ, Akinlabi ET (2016) Microstructure and wear characterization of aluminum matrix composites reinforced with industrial waste fly ash particulates synthesized by friction stir processing. Mater Charact 118:149-158

16. Basavarajappa S, Chandramohan G, Mukund K, Ashwin M, Prabu M (2006) Dry sliding wear behavior of Al 2219/SiCp-Gr hybrid metal matrix composites. J Mater Eng Perform 15(6):668-674

17. Samal P, Vundavilli PR, Meher A, Mahapatra MM (2019) Influence of TiC on dry sliding wear and mechanical properties of in situ synthesized AA5052 metal matrix composites. J Compos Mater 53(28-30):4323-4336

18. Kar C, Surekha B (2019) Effect of red mud and TiC on friction and wear characteristics of Al 7075 metal matrix composites. Aust J Mech Eng. https://doi.org/10.1080/14484 846.2019.1651138

19. Dwiwedi SK, Srivastava AK, Chopkar M (2019) Fabrication and dry sliding wear study of Al6061/mussel-shell particulate composites. SN Appl Sci 1(7):1-13 
20. Chinnamahammad Bhasha A, Balamurugan K (2019) Fabrication and property evaluation of $\mathrm{Al} 6061+\mathrm{x} \%(\mathrm{RHA}+\mathrm{TiC})$ hybrid metal matrix composite. SN Appl Sci 1(9):1-9

21. Zhang Z, Chen DL (2008) Contribution of Orowan strengthening effect in particulate-reinforced metal matrix nanocomposites. Mater Sci Eng, A 484:148-152

22. Ravikumar K, Kiran K, Sreebalaji VS (2017) Characterization of mechanical properties of aluminium/tungsten carbide composites. Measurement 102:142-149

23. Sharma S, Nanda T, Pandey OP (2019) Investigation of T4 and T6 heat treatment on the wear properties of sillimanite reinforced LM30 aluminium alloy composites. Wear 426-427:27-36
24. Bowden FP, Tabor D (1950) The friction and lubrication of solids. Oxford University Press, Oxford

Publisher's Note Springer Nature remains neutral with regard to jurisdictional claims in published maps and institutional affiliations. 